\title{
Editorial
}

\section{Formulation and compatibility studies are important}

Phil Wiffen

In this special online-only issue we are focusing entirely on articles which provide valuable information on formulation, compatibility and stability issues of medicines often used in ways that go beyond the norm. Formulation has always been an important skill for pharmacists since the early days of apothecaries. The term 'secundum artem' will be familiar to older members of the profession, meaning in accordance with the standard procedure

Correspondence to Professor Phil Wiffen, Pain Research Unit, Churchill Hospital, Oxford OX3 7LE, UK; phil.wiffen@ndcn.ox.ac.uk of a profession'. In other words it was expected that the pharmacist would have the skills required to make a particular mixture or topical product and the prescriber merely stated the active ingredients required.

While papers about formulations and compatibilities are an important part of the science of pharmacy, it has to be said that they rarely make riveting reading. That is not the point, they provide a rich resource for pharmacists who are looking to use a similar product in their practice.
We always aim to incorporate a few such articles in each issue of European Journal of Hospital Pharmacy but not enough to prevent something of a backlog of papers that deserve to be published as soon as possible.

This online issue seeks to address that in part.

Funding None declared.

Competing interests None declared.

Provenance and peer review Commissioned; internally peer reviewed.

(c) European Association of Hospital Pharmacists 2018. No commercial re-use. See rights and permissions. Published by BMJ.

\section{A Check for updates}

To cite Wiffen P. Eur J Hosp Pharm 2018;25:e82.

Eur J Hosp Pharm 2018;25:e82.

doi:10.1136/ejhpharm-2018-001727 